\title{
Análise das práticas de gestão PDP em empresas de um polo industrial de revestimento cerâmico
}

\author{
Marcela Avelina Bataghin Costa ${ }^{a *}$, José Carlos de Toledo \\ a*marcelavelina@dep.ufscar.br, UFSCar, Brasil \\ btoledo@dep.ufscar.br, UFSCar, Brasil
}

\begin{abstract}
Resumo
0 artigo analisa a gestão do processo de desenvolvimento de produtos (PDP) em uma amostra de empresas de revestimento cerâmico do Polo de Santa Gertrudes-SP, focando as práticas adotadas e os problemas dessa gestão. Realizou-se uma pesquisa de levantamento (survey), por meio de visitas e entrevistas em 20 de um universo de 36 empresas, de diferentes portes, sediadas no polo, seguida da compilação e análise estatística dos dados. As análises de grupo e de correlação apontaram a existência de dois grupos distintos de empresas com relação às características gerais diferenciados principalmente com relação à formalização das atividades do PDP. Observou-se também que, no geral, as empresas são pouco estruturadas com relação à gestão do PDP, utilizam poucas ferramentas de apoio a essa gestão e para o desenvolvimento de novos produtos dependem tecnologicamente da capacidade de inovação dos fornecedores, principalmente dos produtores de esmaltes (colorifícios).
\end{abstract}

Palavras-chave

Processo de desenvolvimento de produtos. Revestimento cerâmico. Polo de Santa Gertrudes. Gestão do desenvolvimento de produtos.

\section{Introdução}

A capacidade de inovar e desenvolver novos produtos orientados para o mercado e de renovar periodicamente os produtos já oferecidos tem sido vital para a capacidade competitiva em diversos setores industriais. 0 processo de desenvolvimento de produto (PDP), embora complexo, é um processo importante para as empresas, formalizando e orientando a realização das etapas e atividades, buscando contribuir para a qualidade, redução de custo e prazos de lançamento de novos produtos no mercado.

Desse modo, constitui um dos mais importantes processos empresariais, pois dele dependem a renovação do portfólio de produtos da empresa e as vendas futuras, garantindo, assim, a permanência da empresa no mercado. A habilidade para identificar oportunidades de mercado, direcionar esforços de desenvolvimento e levar ao mercado novos produtos e processos rapidamente é critica para a competitividade (CLARK; WHEELWRIGHT, 1993).
Diversos esforços e métodos têm sido propostos para a melhoria do desempenho estratégico e operacional do PDP. Novas estratégias, metodologias e ferramentas são criadas e aplicadas na sua gestão, buscando para este processo uma melhoria de desempenho.

Para Cooper (2000), para serem bem sucedidas no mercado, as empresas devem desenvolver um produto diferenciado com benefícios únicos para o cliente e valor superior ao dos concorrentes.

As abordagens e práticas de gestão do PDP possuem fatores gerais, independentes do setor industrial, mas também fatores que são específicos e condicionados pela realidade da empresa e do setor. Nesse sentido é relevante o estudo e conhecimento das práticas e da realidade dessa gestão por setor industrial. Neste artigo será focado a gestão do PDP em empresas fabricantes de revestimento cerâmico do Polo de Santa Gertrudes, estado de São Paulo. 
Segundo dados da Associação Nacional dos Fabricantes de Revestimento Cerâmico (ASSOCIAÇÃO..., 2009), o Brasil é um dos principais produtores do mundo. Por sua vez, o Polo de Santa Gertrudes é responsável por cerca de 50\% da produção nacional e por 15\% do total das exportações brasileiras de revestimentos cerâmicos.

No entanto, os revestimentos cerâmicos têm enfrentado cada vez mais a concorrência de países como a Espanha e a ltália, que têm maior competitividade tecnológica. Além da concorrência com a indústria da Índia e da China, que são tradicionalmente competitivas em custos.

Dada a importância do Polo de Santa Gertrudes na produção de revestimento cerâmico no Brasil e no estado de São Paulo, e devido às oportunidades existentes de melhorar a competitividade do polo por meio de melhorias na capacidade de desenvolvimento de novos produtos, justificou-se a realização de um estudo sobre o processo de desenvolvimento de produto nas empresas integrantes.

Segundo Minuzzi (2001), as características próprias das empresas da região, tais como a predominância de empresas familiares ou ainda em fase de transição para uma gestão mais profissional, e seu histórico de crescimento e consolidação no mercado requerem contribuições teóricas específicas para esse segmento industrial no desenvolvimento de produtos. Particularmente, é relevante diminuir a dependência tecnológica dessas empresas no processo de desenvolvimento de produtos (PDP) em relação às multinacionais fornecedoras de insumos químicos.

Buscou-se, portanto, identificar em empresas do polo práticas existentes e possíveis limitações que dificultam um melhor e mais ágil processo de desenvolvimento de novos produtos. É relevante conhecer as práticas atuais de desenvolvimento de produto nessas empresas e, assim, identificar os possiveis problemas e as necessidades de melhorias no PDP. Desse modo pode-se, a partir do conhecimento dessa realidade, pensar em sugestões específicas para a melhoria do PDP dessas empresas, compor políticas públicas para as empresa do polo e, eventualmente, para o setor no país. Além disso, o conhecimento adquirido poderá fornecer subsídios para a capacitação de pessoal que atua no setor.

0 artigo está estruturado da seguinte forma: na próxima seção são discutidos e apresentados conceitos sobre a gestão do PDP. Na terceira seção é abordada a indústria de revestimentos cerâmicos no Brasil e no Polo de Santa Gertrudes. Na quarta seção, o método de pesquisa é descrito. Na quinta seção são apresentados os resultados da pesquisa aplicada junto ao setor de revestimentos cerâmicos. Na sexta seção são feitas proposições e sugestões de melhorias para o PDP das empresas do polo. $\mathrm{Na}$ última seção são apresentadas as considerações finais.

\section{A gestão do processo de desenvolvimento de produtos}

0 processo de desenvolvimento de produtos pode ser definido como um conjunto de atividades envolvendo quase todas as áreas funcionais da empresa e sua cadeia de suprimentos, que têm como objetivo a transformação de necessidades de mercado em produtos ou serviços economicamente viáveis (KAMINSKl, 2000).

De acordo com Rozenfeld et al. (2006), o PDP situa-se na interface entre a empresa e o mercado, identificando suas reais e futuras necessidades e procurando atendê-las por meio de produtos e serviços oferecidos.

Para Toledo et al. (2006), o PDP engloba as atividades de elaboração das especificações de projeto do produto e de seu processo de produção e é finalizado com as atividades de acompanhamento do produto no mercado, após seu lançamento, e com as atividades de descontinuidade do produto no mercado. De maneira geral, o PDP abrange todo o ciclo de vida do produto.

A eficácia da gestão do PDP permite que as empresas percebam mudanças nos hábitos dos consumidores e identifiquem novas tendências, criem barreiras à entrada de concorrentes, conseguindo uma maior flexibilidade e explorando oportunidades em novos mercados.

Segundo Wheelwright e Clark (1994), uma das maneiras mais úteis de se classificar os tipos de projeto de desenvolvimento é por meio do grau de mudanças que eles incorporam, já que essa classificação permite entender as dificuldades, a complexidade e o grau de comprometimento de recursos envolvidos no projeto. Esses autores classificam os processos de desenvolvimento de acordo com o grau de inovação do produto e do processo. Tal classificação, apresentada abaixo, foi utilizada neste trabalho, uma vez que considera-se que o tipo de projeto influencia as práticas de gestão.

- Projetos de desenvolvimento ou pesquisa avançada: têm por objetivo criar conhecimento (know-how) para futuros projetos. Em muitas organizações esses projetos são desenvolvidos por uma estrutura organizacional própria, com recursos e equipamentos específicos;

- Projetos incrementais ou derivados: envolvem projetos que criam produtos e processos que são derivados, híbridos ou representam pequenas modificações em relação aos já existentes. Esses 
projetos não necessitam de muitos esforços já que tratam de alterações em tecnologias já dominadas pela empresa;

- Projetos radicais (breakthrough): Envolvem significativas modificações no projeto do produto ou do processo já existente, diferindo fundamentalmente das gerações de projetos anteriores, podendo criar um novo núcleo ou nova categoria de produtos para a empresa. Como geralmente são incorporadas novas tecnologias ou materiais, eles requerem um processo de manufatura inovador;

- Projetos plataforma: se enquadram entre os incrementais e os radicais. São realizadas alterações representativas no projeto do produto e/ou do processo, mas sem a introdução de novas tecnologias ou materiais como nos projetos radicais. Plataforma significa um projeto que serve de base para uma família de produtos. Meyer (1997), Meyer e Lehnerd (1997) e Cheng e Melo Filho (2007) citam que é comum encontrar nas empresas a divisão de produtos por famílias, tendo como critério a plataforma, ou seja, uma base comum de tecnologia; e

- Projetos de alianças ou parcerias: são desenvolvidos tendo em sua essência um objetivo estratégico, tal como aprender uma nova tecnologia ou aproveitar uma oportunidade de mercado. Pode ser conduzido fora do âmbito da organização ou em parceria com outras empresas.

\subsection{Dimensões do PDP}

Segundo Kahn, Barczak e Moss (2006), o PDP, por sua complexidade, pode ser representado, e observado, por meio de múltiplas dimensões compostas por características e aspectos relevantes para a gestão desse processo. Essas dimensões representam perspectivas para se compreender o PDP nas empresas, além de ajudar no direcionamento de possíveis ações de melhoria.

Neste artigo adotam-se as quatro dimensões propostas por Rozenfeld, Amaral e Toledo (2000) e Rozenfeld et al. (2006), por se considerar que essas são adequadas e suficientes para analisar o PDP nas empresas de revestimento cerâmico do polo. As dimensões apresentadas em Rozenfeld et al. (2006) abordam itens que permitem avaliar a gestão do PDP de uma maneira objetiva, o que facilita a alocação das características do PDP das empresas estudadas em tais dimensões, já que tais empresas apresentam, em geral, estruturas e processos organizacionais simples.

As quatro dimensões do PDP consideradas são:

- Dimensão estratégica: fornece orientação para gerenciamento do portfólio de produtos e projetos e para a realização de avaliações de desempenho dos projetos. Nessa dimensão são consideradas atividades como pesquisa de mercado; gestão de portfólio; renovação dos projetos plataformas; integração interfuncional na organização/empresa; alianças estratégicas com parceiros e avaliação de desempenho do PDP;

- Dimensão organizacional: se refere aos arranjos organizacionais adotados pela empresa na condução dos projetos. Os principais tipos são: estrutura funcional, estrutura matricial e estrutura por projeto;

- Dimensão atividades: trata basicamente das atividades realizadas ao longo das fases do PDP, com maior ou menor paralelismo conforme as especificidades do processo de cada tipo de empresa e as informações manuseadas na execução destas atividades. 0 PDP pode ser estruturado em macrofases, fases e atividades. As macrofases e as fases do PDP, são:

1) Pré-desenvolvimento: gestão do planejamento estratégico dos produtos e planejamento do projeto;

2) Desenvolvimento: projeto informacional, projeto conceitual, projeto detalhado, preparação da produção e lançamento do produto; e

3) Pós-desenvolvimento: acompanhar produto e processo, descontinuar produto.

- Dimensão recursos: se refere à disponibilidade e uso de ferramentas e métodos, de foco organizacional ou estatístico, que apoiam as ações e decisões nas diferentes atividades do PDP, tais como Quality Function Deployment - QFD, engenharia de valor, método Taguchi, FMEA etc., além de ferramentas tecnológicas tais como CAD, CAE e CAM.

As questões abordadas no instrumento de pesquisa (questionário) e analisadas na amostra de empresas foram baseadas nessas quatro dimensões da gestão do PDP.

\section{A indústria de revestimento cerâmico e o Polo de Santa Gertrudes}

Em 2008 foram produzidos 713,4 milhões e vendidos 686,8 milhões de metros quadrados (mercado interno mais exportações) de cerâmica de revestimento. As vendas totais tiveram crescimento de $8 \%$ no ano de 2008 , em relação a 2007, no entanto essa porcentagem de crescimento foi menor que no ano anterior, o que se justifica pela crise mundial ocorrida no final de 2008 e início de 2009 (ASSOCIAÇÃO..., 2009).

De acordo com Garcia e Silva (2007), o setor de revestimentos cerâmicos no Brasil é bastante heterogêneo, possui empresas de grande, médio e pequeno porte, controladas por capital nacional, que produzem todos os tipos de produtos cerâmicos, desde os de maior qualidade (produzidos pelo processo de moagem a úmido) até aqueles que competem via preço (produzidos pelo processo de moagem a seco). 
Segundo a ABNT (ASSOCIAÇÃO..., 2010), os revestimentos cerâmicos são classificados segundo teste de resistência do esmalte da peça ao desgaste por abrasão. Essa classificação é conhecida como PEl (índice de resistência à abrasão), nela são indicados os ambientes mais adequados para sua aplicação. 0 PEl é classificado de 0 a 5, sendo o produto com PEl 1 o menos resistente e o produto com PEI 5 o mais resistente. 0 Quadro 1 apresenta as especificações quanto ao PEl das linhas de produtos citadas neste trabalho. Para elaboração deste quadro foram utilizadas normas do setor e catálogos de várias empresas. Com relação aos outros parâmetros desse produto, tais como nível de absorção de água, resistência a ataques químicos e resistência a produtos manchantes, não foi possivel descrevê-los, pois variam entre as empresas, sem seguir um padrão.

0 Polo Cerâmico de Santa Gertrudes localiza-se no estado de São Paulo e abrange a sua região central, englobando os municípios de: Santa Gertrudes, Cordeirópolis, Rio Claro, Limeira, Araras, Piracicaba e Iracemápolis, situados em um raio de $50 \mathrm{~km}$ em torno da cidade polo. É constituído por 36 empresas produtoras de revestimento cerâmico.

Segundo Vicari et al. (2005), o desenvolvimento do polo de revestimentos cerâmicos de Santa Gertrudes se deu pela descoberta de uma argila com características especiais que tornavam o processo produtivo mais fácil e barato (processo de moagem via seca). Assim as empresas começaram a se estabelecer na região, produzindo telhas e tijolos. Esses produtores começaram a perceber a necessidade de agregar valor e se adaptar às exigências do mercado consumidor e começaram a produzir outros itens ligados à revestimento cerâmicos. Entretanto, manteve-se o foco em custos baixos.

Quadro 1. Linhas de revestimento cerâmico e PEl.

\begin{tabular}{|c|c|c|c|}
\hline Linhas & PEl & Linhas & PEl \\
\hline $\begin{array}{l}\text { Brilhante } \\
\text { pavimentado }\end{array}$ & 4 & Linha pastilha & 4 \\
\hline $\begin{array}{l}\text { Brilhante } \\
\text { revestimento }\end{array}$ & $3 / 4$ & Linha pedra & $4 / 5$ \\
\hline Linha bambu & 4 & Linha terra & $3 / 4$ \\
\hline $\begin{array}{l}\text { Linha } \\
\text { coordenada }\end{array}$ & $3 / 4$ & $\begin{array}{c}\text { Mate } \\
\text { pavimentado }\end{array}$ & 4 \\
\hline Linha decorada & 4 & $\begin{array}{l}\text { Mate } \\
\text { revestimento }\end{array}$ & $4 / 3$ \\
\hline $\begin{array}{l}\text { Linha } \\
\text { geométrica }\end{array}$ & 4 & Porcelanato & $4 / 5$ \\
\hline Linha granilhas & 5 & $\begin{array}{c}\text { Rústico } \\
\text { pavimentado }\end{array}$ & 4 \\
\hline Linha madeira & 3 & $\begin{array}{l}\text { Rústico } \\
\text { revestimento }\end{array}$ & 4 \\
\hline $\begin{array}{l}\text { Linha } \\
\text { marmorizada }\end{array}$ & 2 & & \\
\hline
\end{tabular}

Fonte: Elaborado pelos autores.
Nos últimos anos, os investimentos dirigiram-se à expansão da capacidade produtiva por intermédio de aquisição, instalação de novas plantas e modernização de plantas já existentes. No entanto, a capacidade de desenvolvimento e inovação de produtos dessas empresas é fortemente atrelada à capacidade de inovação dos fornecedores, principalmente de colorifícios. 0 maior desafio das empresas atualmente é tornarem-se competitivas em inovação, design e comercialização dos produtos.

\section{Método de pesquisa}

0 método de pesquisa adotado é a pesquisa bibliográfica, seguida de uma pesquisa de campo de levantamento (survey) e posterior análise dos dados. 0 survey se propõe a descrever e analisar a gestão do processo de desenvolvimento de produtos em uma amostra de empresas de revestimento cerâmico do Polo de Santa Gertrudes-São Paulo.

As técnicas de pesquisa utilizadas são: pesquisa bibliográfica e documental, definição e teste do questionário (semiestruturado) para levantamento dos dados, aplicação do questionário em visita às empresas, compilação de dados e análise dos resultados. A coleta de dados ocorreu por meio de visita pessoal às empresas da amostra, durante o ano de 2009. A partir dos dados levantados e compilados, as conclusões derivadas foram discutidas com profissionais das empresas.

De um total de 36 empresas identificadas no polo, foram visitadas e entrevistadas 20 . Não foi possível a obtenção de questionários de um número maior de empresas tendo em vista que, devido à concorrência direta, algumas empresas optaram por não participar da pesquisa. Outras foram afetadas pela crise internacional ocorrida no período (2008-2009), interrompendo uma ou mais de suas linhas ou unidades de produção, o que impossibilitou a visita e aplicação do questionário nessas unidades. Foram entrevistados os gerentes ou responsáveis pelo desenvolvimento de produto dessas empresas.

\section{Apresentação dos dados da pesquisa de campo}

\subsection{Caracterização geral das empresas da amostra}

De acordo com os dados obtidos das empresas da amostra, 5\% (1 em 20) das empresas são de pequeno porte, ou seja, possuem entre 20 e 99 funcionários, 85\% (17) são de médio porte, possuindo entre 100 e 499 funcionários, e 10\% (2) são de grande porte, com mais de 500 funcionários. 
Todas as empresas da amostra são de capital nacional e em apenas 10\% delas a administração é profissional. Os produtos fabricados pelas empresas são basicamente pisos e revestimentos.

0 faturamento médio anual das empresas da amostra, no período de 2007 a 2009, concentra-se na faixa de $40 \mathrm{R} \$$ milhões a $100 \mathrm{R} \$$ milhões. Para todas as empresas da amostra há a percepção de que o retorno financeiro advindo de novos produtos lançados no mercado está dentro das expectativas. No entanto, $40 \%$ das empresas não sabem mensurar o quanto do faturamento médio anual advêm de novos produtos, lançados nos três anos anteriores à pesquisa de campo, visto que alguns dos revestimentos despontam como sucesso de vendas, permanecendo no mercado por mais de 10 anos, enquanto outros vendem durante apenas alguns meses e são retirados do mercado. Ou seja, alguns produtos estão sempre na moda enquanto para outros a moda é passageira. As outras empresas (60\%) têm uma ideia apenas aproximada da porcentagem do faturamento advinda de novos produtos nos três anos anteriores, conforme pode ser visto na Tabela 1. Observa-se uma significativa variação na percepção dessa porcentagem de sucesso entre as empresas, variando de 33\% a 100\% dos produtos lançados.

0 principal mercado de atuação das empresas é o mercado nacional, sendo os estados do Sudeste os maiores consumidores.

Para a maior parte das empresas da amostra, desenvolver um novo produto significa renovar sua linha de produtos de modo a satisfazer as necessidades dos consumidores e conquistar novos mercados.

\subsection{Análise de correlação}

A pesquisa de campo gerou dados que foram sistematizados e analisados por meio de técnicas estatísticas. Confrontando-se todas as variáveis e

Tabela 1. Porcentagem de produtos avaliados como sucesso de vendas lançados nos últimos 3 anos.

\begin{tabular}{cccc}
\hline Empresa & $\begin{array}{c}2007 \\
(\%)\end{array}$ & $\begin{array}{c}2008 \\
(\%)\end{array}$ & $\begin{array}{c}2009(\%) \\
\text { (até o momento da pesquisa) }\end{array}$ \\
\hline A & 50 & 50 & - \\
B & 34 & 67 & - \\
C & 50 & 50 & 75 \\
D & 60 & 60 & - \\
E & - & - & 15 \\
F & 40 & 50 & - \\
G & 60 & 100 & - \\
H & 40 & 40 & - \\
I & 50 & 50 & - \\
J & 75 & 90 & 90 \\
K & 33 & 33 & 33 \\
L & 70 & 90 & - \\
\hline
\end{tabular}

levando-se em consideração a significância de pelo menos 95\% nas correlações, podem-se observar algumas considerações sobre a gestão do PDP na amostra de empresas. As mais significativas são descritas a seguir e mostradas na Tabela 2 .

0 tipo de administração (se familiar, profissional, mista ou em transição) é fortemente correlacionado com os principais mercados (nacional ou internacional) em que a empresa atua. Essa correlação pode ser considerada muito forte. As empresas com administração familiar atuam basicamente no mercado nacional, não exportando a produção. Apenas quatro (25\%) das 16 empresas com administração tipo familiar exportam seus produtos, e o percentual do valor da exportação no faturamento total dessas empresas é inferior a 10\%, ou seja, relativamente pouco significativo. Como as empresas são administradas tradicionalmente por membros das famílias fundadoras, existe, de certa forma, uma grande preocupação em manter a empresa em funcionamento e se arriscar no mercado internacional, influenciado por oscilações do dólar e constantes crises econômicas, tende a ser considerado por essas empresas um risco ao bom funcionamento e sobrevivência. De um modo geral também se pode perceber que as empresas do polo, independente do tipo de administração, não têm capacidade instalada para abastecer o mercado interno e comercializar em grande quantidade no mercado externo, outras não possuem preço e qualidade competitivos com empresas internacionais.

0 tipo de administração também está relacionado de forma positiva com o tipo de projeto desenvolvido pelas empresas. Conforme evidenciado na pesquisa de campo, nas empresas de administração tipicamente familiar a alta administração bem como os responsáveis pelo PDP tenderiam a ter uma postura mais conservadora quanto ao lançamento de novos produtos considerando ser mais vantajoso tentar desenvolver novos produtos explorando os moldes que já possuem (de produtos desenvolvidos anteriormente), que são de custo relativamente elevados, se limitando a desenvolvimentos com pequenas modificações nos produtos já existentes, basicamente na sua estética, procurando maximizar o retorno desse investimento.

0 desenvolvimento de projetos que busquem novas soluções para revestimentos cerâmicos é considerado, por essas empresas, como caro e demorado, podendo durar de cerca de oito meses a um ano. Além disso, elas possuem parcerias com fornecedores de colorifícios e com empresas de design, que realizam atividades de pesquisa e desenvolvimento buscando inovações de produto que são repassadas a essas empresas fabricantes de revestimento cerâmico, o que restringe e condiciona as atividades internas de desenvolvimento de produto. 
Tabela 2. Correlações significativas para $p<0,05$.

\begin{tabular}{|c|c|c|c|c|c|c|c|c|c|c|c|c|c|c|}
\hline & & 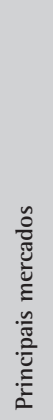 & 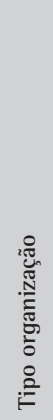 & 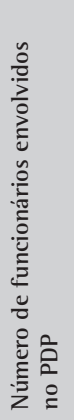 & 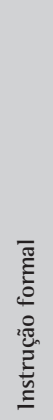 & $\begin{array}{l}\frac{0}{0} \\
\frac{0}{0} \\
\frac{0}{2} \\
\frac{0}{0} \\
\tilde{y} \\
\frac{0}{2} \\
\tilde{J}\end{array}$ & 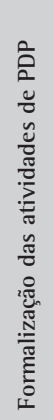 & 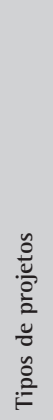 & 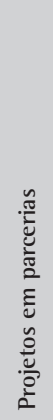 & 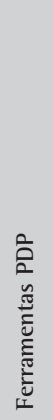 & 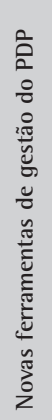 & 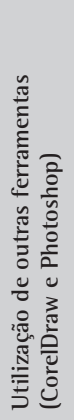 & 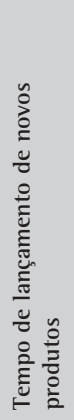 & 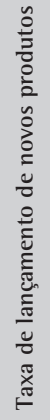 \\
\hline \multirow{3}{*}{$\begin{array}{l}\text { Características gerais } \\
\text { da empresa }\end{array}$} & Tipo de administração & 0,9 & - & - & - & 0,7 & 0,8 & 0,6 & - & - & - & - & - & 0,8 \\
\hline & Número de funcionários & - & - & 0,9 & - & - & - & - & - & - & - & - & 0,7 & - \\
\hline & Principais mercados & _- & - & _- & 0,9 & _- & 0,9 & _- & _- & _- & _- & _- & _- & - \\
\hline \multirow{6}{*}{ Características do PDP } & $\begin{array}{l}\mathrm{N}^{\circ} \text { de funcionários } \\
\text { envolvidos no PDP }\end{array}$ & - & - & - & - & 0,4 & 0,7 & - & - & - & - & - & 0,6 & - \\
\hline & $\begin{array}{l}\text { Funcionários com instrução } \\
\text { formal }\end{array}$ & - & - & - & - & 0,5 & 0,6 & 0,6 & - & 0,4 & 0,4 & - & - & - \\
\hline & Equipes de projeto & - & - & - & - & - & - & - & - & - & - & - & 0,5 & - \\
\hline & $\begin{array}{l}\text { Formalização das atividades } \\
\text { do PDP }\end{array}$ & - & - & - & - & 0,5 & - & - & - & - & - & - & - & - \\
\hline & Tipos de projetos & - & 0,7 & - & - & - & - & - & - & - & - & - & - & - \\
\hline & Parcerias nos projetos & _ & 0,5 & _ & _- & _- & _- & 0,5 & _- & 0,8 & _- & _- & _- & _- \\
\hline \multirow{2}{*}{$\begin{array}{l}\text { Lançamento de novos } \\
\text { produtos }\end{array}$} & $\begin{array}{l}\text { Tempo de lançamento de } \\
\text { novos produtos }\end{array}$ & - & - & - & - & - & - & - & 0,4 & - & - & - & - & - \\
\hline & $\begin{array}{l}\text { Taxa de lançamento de } \\
\text { novos produtos }\end{array}$ & - & - & - & - & 0,6 & 0,6 & - & - & - & 0,7 & - & - & - \\
\hline
\end{tabular}

Fonte: Software Statistica 8.0.

0 tipo de administração também correlaciona-se fortemente com a taxa de novos produtos lançados no mercado. As empresas com maior variedade de produtos são geralmente as de administração familiar. lsso, por outro lado, pode ocorrer devido ao fato de que essas empresas, na amostra, são as mais antigas e tradicionais no mercado do polo. Sendo mais conhecidas e tendo um mercado maior, possuem maiores possibilidades financeiras para apresentar maior variedade de novos produtos. Consequentemente, a maior variedade de produtos acarreta em mais vendas, já que a empresa consegue atingir nichos diferentes de mercado.

0 número total de funcionários está correlacionado positivamente com o tempo de lançamento de novos produtos. Nota-se que quanto maior o número de funcionários menor é o tempo de lançamento de novos produtos. Essa relação pode ser causada pela presença de funcionários de diferentes áreas de formação e conhecimento contribuindo com ideias diferentes e informações relevantes para o desenvolvimento. As empresas maiores geralmente possuem um número maior de profissionais mais qualificados, em diversas áreas funcionais, que podem contribuir com novas soluções para o desenvolvimento de produto, além de possuírem maior quantidade de pessoal na produção, o que agiliza a fabricação e distribuição de novos produtos.
Os tipos de mercado também aparecem correlacionados com o nível de instrução formal dos funcionários envolvidos no PDP da empresa. $\mathrm{Na}$ maioria das empresas que atuam somente no mercado nacional, o grau de instrução formal dos funcionários dedicados ao desenvolvimento de novos produtos é de no máximo graduação, já nas empresas que trabalham com o mercado internacional encontrou-se também nos departamentos de desenvolvimento de produtos profissionais com mestrado e doutorado. Essa constatação pode estar relacionada ao fato de que as empresas que atuam no mercado internacional necessitam de pessoas com nível mais elevado de qualificação para realizarem as articulações, mais complexas, entre clientes e fornecedores, e contribuirem para melhor atender os requisitos do mercado externo. São necessárias pessoas com maior conhecimento em economia, línguas estrangeiras, legislação, certificação dos produtos, normas técnicas, entre outros.

Quanto ao tipo de organização das equipes de projeto ou da estrutura do PDP, esse aparece correlacionado positivamente com o grau de formalização das atividades do PDP. Embora apenas nove $(45 \%)$ das empresas tenham as atividades do PDP formalizadas, todas as empresas com tipo de organização por projeto possuem tais atividades formalizadas, o que evidencia que quanto maior a 
formalização das atividades, mais organizados são os mecanismos de comunicação e coordenação utilizados pela equipe na condução dos projetos.

A correlação entre o tipo de organização do PDP e a perspectiva de utilização de novas ferramentas apresentou um valor alto, podendo ser considerada significativa, já que oito empresas, dentre as com PDP considerado organizado de forma mais adequada, demonstraram interesse em implantar novas ferramentas de gestão e apoio ao PDP.

A correlação entre o número de funcionários envolvidos com o PDP e a formação de equipes de projeto pode ser considerada moderada. Metade das empresas que afirmaram utilizar equipes de projeto possuem em média sete funcionários envolvidos diretamente com o PDP, o que chega a ser o dobro do número de funcionários com essa função nas empresas que não adotam equipes de projeto. Isso evidencia que quanto maior o número de funcionários ligados ao PDP, maior a probabilidade de a empresa formar tais equipes.

A correlação entre número de funcionários envolvidos diretamente com o PDP e o grau de formalização das atividades do PDP é considerada forte, ou seja, quanto maior a quantidade de funcionários do PDP, maior o grau de formalização das atividades de PDP. Isso se deve ao fato de que o maior número de pessoas ligadas à função torna necessária uma padronização da comunicação e dos procedimentos a serem realizados, de modo a garantir a eficiência do processo.

0 número maior de funcionários envolvidos diretamente com o PDP influencia no tempo para lançamento de novos produtos no mercado. Quanto maior o número de funcionários dedicados exclusivamente ao desenvolvimento de novos produtos, menor é o tempo de lançamento.

0 nível de instrução formal dos funcionários dedicados ao desenvolvimento de produto está correlacionado com a existência de equipes de projeto e à formalização das atividades do PDP. 0 que se pôde observar é que em todas as empresas nas quais existem equipes e formalização das atividades de PDP ocorre a presença de pessoal com, no mínimo, formação de nível superior. Além disso, a instrução formal também está relacionada positivamente ao tipo de projeto conduzido pelas empresas. Quanto maior o nível de instrução formal dos funcionários envolvidos com o PDP, mais elaborados e complexos tendem a ser os projetos. Uma dessas empresas conduz um projeto de pesquisa e desenvolvimento avançado. lsto mostra que quanto maior a qualificação do pessoal do PDP da empresa, na amostra, melhor estruturada e com o processo formalizado ela se encontra.
Também se pôde observar que embora poucas empresas utilizem alguma ferramenta de gestão de suporte ao PDP, aquelas que pelo menos conhecem algumas dessas ferramentas ou no futuro pretendem implantar alguma são as que possuem internamente pessoal com nível de instrução formal mais elevado (mestres e doutores).

0 tipo de projeto também se correlaciona com o tipo de organização das equipes de projeto e da estrutura do PDP. A maioria das empresas é organizada funcionalmente e desenvolve projetos do tipo incremental ou derivado. Uma das poucas empresas organizadas por projeto foi a única que, como citado anteriormente, praticava projeto de desenvolvimento e pesquisa avançada. Isso evidencia que à medida que essas empresas se tornam melhor organizadas a capacidade para desenvolver projetos de maior complexidade pode aumentar.

0 número de novos produtos lançados é maior nas empresas em que existem equipes de projeto e, principalmente, nas empresas em que as atividades do PDP são realizadas de maneira mais formal. Também se percebe nas empresas em que há um maior número de lançamentos que existe uma tendência maior de, num futuro próximo, aumentar a aplicação de ferramentas de gestão de apoio ao PDP.

\subsection{Análise de agrupamento}

Buscando agrupar as empresas da amostra por características semelhantes, foi realizada uma análise de agrupamento, com o auxílio do software Statistica 8.0. Para realizar a análise foram escolhidas algumas questões do questionário aplicado na pesquisa de campo. As questões 15, 16 e 20, que dizem respeito à formalização das atividades de PDP nas empresas; as questões 23,35 e 37 , que estão associadas à utilização de ferramentas e técnicas de gestão do PDP; e as questões 28 e 29 , que se referem à quantidade e tempo de lançamento de novos produtos. Baseado nas respostas obtidas para cada uma dessas questões foi realizado, no Statistica 8.0, a análise de agrupamento por k means, que forma os grupos (agrupamentos) com base na média das respostas.

Optou-se pela formação de dois agrupamentos (em função do número limitado de empresas e de um relativo grau de semelhança entre elas), obtendo-se os seguintes agrupamentos: grupo 1, composto por 14 empresas (70\% da amostra); e grupo 2 , composto por 6 empresas (30\% da amostra). Por meio da consideração do $p$-valor, fornecido pela análise de variância, analisou-se a diferenciação dos agrupamentos. Quanto menor o $p$-valor, maior a capacidade de discernimento dos grupos em relação à variável considerada. A Tabela 3 mostra os valores 
de $p$ para cada uma das questões (variáveis) citadas acima. As questões que possuem maior capacidade para a diferenciação dos agrupamentos são: 20, 23, 28, 35 e 37.

A Figura 1 representa o gráfico gerado com o software Statistica e mostra a distância entre os dois agrupamentos para cada uma dessas variáveis (questões do questionário).

\subsubsection{Grupo 1}

As empresas pertencentes ao grupo 1 são, predominantemente, de administração familiar $(85,7 \%)$. As empresas de médio e grande porte também são maioria nesse grupo (92,8\%). Dessas, apenas 14,2\% exportam seus produtos e a participação do valor total das exportações no faturamento da empresa é inferior a $10 \%$. Desse modo as empresas desse grupo se caracterizam por atuarem basicamente no mercado nacional.

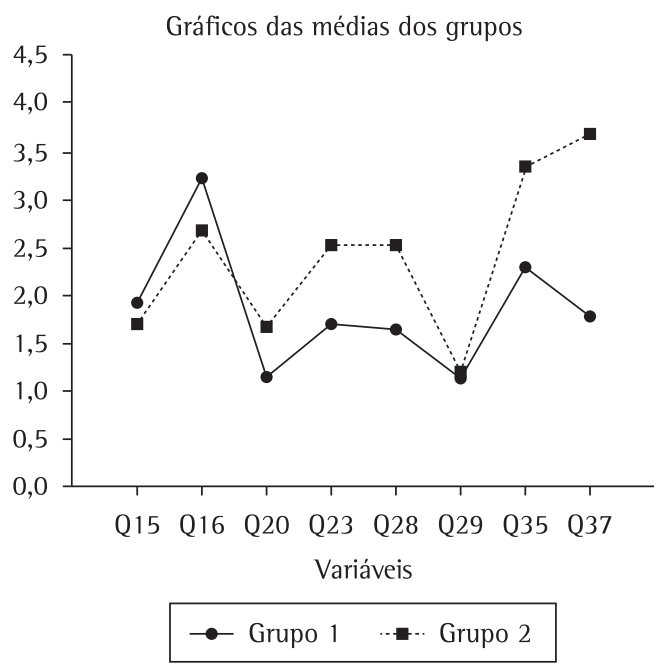

Figura 1. Valores das variáveis para cada grupo. Fonte: software Statistica 8.0.
Na maior parte das empresas do grupo 1 (85,7\%) não existem equipes de projeto. $\mathrm{E} 71,4 \%$ das empresas não possuem procedimentos formalizados que definem as atividades de PDP.

A maioria dos projetos desenvolvidos pelas empresas (em média 71,4\% dos projetos das empresas) desse grupo são do tipo incremental ou derivado, que envolvem pequenas modificações em projetos já existentes. Este fato ocorre devido às limitações tecnológicas e técnicas das empresas, sendo mais rentável atuar de forma defensiva, evitando gastos e riscos de insucesso. Além disso, metade das empresas desse grupo não desenvolve nenhum tipo de projeto de desenvolvimento e pesquisa avançada, não criando nenhum tipo de novo conhecimento para futuros projetos. lsto ocorre, principalmente, por fatores financeiros e por uma postura estratégica conservadora.

Com relação às ferramentas e métodos de apoio ao PDP, as mais conhecidas por este grupo são: FMEA, QFD, benchmarking, CAD e engenharia de valor. Embora conhecidas, grande parte das empresas não utiliza tais ferramentas. TRIZ, CAPP e tecnologia de grupo são desconhecidas por $71,4 \%$ das empresas. Em 14,2\% das empresas a ferramenta FMEA está totalmente implantada; em 7,1\% está em processo de implantação; e para 14,2\% das empresas a sua implantação está nos planos. 0 QFD é utilizado em $7,1 \%$ das empresas e está nos planos de implantação de outra empresa. 0 benchmarking e o CAD estão totalmente implantados em $21,4 \%$ das empresas. É importante observar que mais de uma dessas ferramentas citadas podem ser utilizadas ou estar presente nos planos futuros de uma mesma empresa.

Todas as empresas utilizam um ou mais indicadores de desempenho para avaliar o desenvolvimento de novos produtos, sendo os mais citados: a porcentagem do faturamento advinda de novos produtos (85,7\% das empresas); satisfação dos clientes quanto aos novos produtos (78,5\% das empresas); porcentagem do lucro advinda de novos produtos (50\% das empresas); custo de desenvolvimento por projeto/produto $(42,9 \%$ das empresas).

Tabela 3. Nível descritivo das variáveis utilizadas na análise de agrupamento.

\begin{tabular}{clc}
\hline $\begin{array}{c}\text { No das } \\
\text { questões }\end{array}$ & \multicolumn{1}{c}{ Questões (variáveis) } & $\begin{array}{c}\text { Nivel } \\
\text { descritivo }\end{array}$ \\
\hline Q15 & Existem equipes de projeto & 0,486275 \\
Q16 & $\begin{array}{l}\text { A empresa possui algum documento formalizado que define as atividades de PDP } \\
\text { Qual a porcentagem média (por ano) que cada um dos tipos de projeto de desenvolvimento de produto representa }\end{array}$ & 0,180709 \\
Q20 & $\begin{array}{l}\text { no total de projetos desenvolvidos pela empresa, considerando os últimos três anos? (Se o tipo de projeto não foi } \\
\text { desenvolvido pela empresa, a porcentagem deve ser zero.) }\end{array}$ & 0,017764 \\
Q23 & Grau de implantação das ferramentas utilizadas na empresa, de acordo com os critérios estabelecidos. & 0,014358 \\
Q28 & Tempo médio de lançamento de um novo produto por tipo de projeto. & 0,035239 \\
Q29 & Número médio de novos produtos lançados por ano. & 0,898241 \\
Q35 & A empresa pretende implantar novas ferramentas de gestão no processo de desenvolvimento de produto? Quais? & 0,010554 \\
Q37 & A empresa utiliza alguma ferramenta e técnica na elaboração dos desenhos para os revestimentos? & 0,000054 \\
\hline
\end{tabular}

Fonte: Software Statistica 8.0. 
Quanto ao tipo de organização das empresas deste grupo, o que mais se aproxima da estrutura de trabalho das equipes de desenvolvimento de produto é, em $85,7 \%$ das empresas, a organização do tipo funcional e, em 14,3\% das empresas, a organização por projeto.

Com relação às expectativas futuras para o processo de desenvolvimento de novos produtos, as principais tendências visualizadas pela maioria das empresas $(71,4 \%)$ do grupo 1 se referem ao aumento do número de lançamento de novos produtos e à possibilidade de acompanhar os ciclos de inovações tecnológicos cada vez mais curtos. Além disso, 64,3\% das empresas pretendem realizar novas parcerias para a condução do PDP. Em 28,6\% das empresas deste grupo existe a intenção de implantar novas ferramentas de apoio à gestão do PDP.

A principal dificuldade apontada pelas empresas do grupo 1 com relação ao desenvolvimento de novos produtos se refere ao alto custo do desenvolvimento tecnológico e de novos materiais necessário ao desenvolvimento. Existem no mercado tecnologias que permitem a decoração sem contato da máquina com a peça e em $100 \%$ da peça, impressão digital em alta definição da imagem (HD), a variação visual ilimitada (Infinity Design) e a impressão em relevos (3D Image). Existe também um equipamento denominado Croma, que aumenta a produtividade das prensas e confere maior definição estética ao porcelanato. Assim, é possível produzir mais, com melhor qualidade, agregando valor ao produto e ampliando a capacidade de produção. No entanto, os investimentos para aquisição dessas tecnologias e equipamentos são considerados altos pelas empresas.

\subsubsection{Grupo 2}

Das 6 empresas deste grupo, $4(66,7 \%)$ são de administração familiar, uma empresa $(16,6 \%)$ de administração profissional e uma (16,6\%) está em transição de administração familiar para profissional. São predominantemente de médio porte $(83,3 \%)$; apenas uma empresa $(16,7 \%)$ é de grande porte.

Metade das empresas do grupo 2 exportam parte da produção para países do Mercosul e África, que são mercados menos concorridos. Em 66,7\% das empresas o percentual do faturamento proveniente da exportação está entre $11 \%$ e $20 \%$. Nas demais empresas (33,3\%), o percentual proveniente das exportações é inferior a 10\% do faturamento.

Em 66,7\% das empresas do grupo 2 existe a formação de equipes para a condução de novos projetos. E 83,4\% das empresas afirmaram possuir algum procedimento documentado que define as atividades do PDP.
Todas as empresas do grupo 2 terceirizam alguma atividade no desenvolvimento de produtos, principalmente as que se referem à criação de novos desenhos. 0 desenvolvimento dos fotolitos e dos rolos de silicone e a criação de matrizes serigráficas são realizados por institutos de design e por fornecedores de esmaltes.

Em uma empresa (16,7\%) do grupo 2, metade dos novos projetos desenvolvidos é do tipo radical, que envolve alterações significativas nos produtos. Essas alterações ocorrem através da introdução de novas tecnologias no processo de fabricação e de novas matérias-primas, principalmente no que se refere aos colorifícios usados no acabamento dos revestimentos. Em duas empresas (33,4\%), todos os projetos conduzidos são do tipo derivado ou incremental. 0 desenvolvimento desse tipo de projeto nas empresas se dá principalmente em razão do baixo custo de investimento, já que são projetos com pequenas modificações em relação aos já desenvolvidos por essas empresas. Apenas uma empresa (16,7\%) afirmou que metade dos novos projetos conduzidos por ela busca criar conhecimentos para futuros projetos, sendo projetos do tipo desenvolvimento e pesquisa avançada. Essa empresa pesquisa o desenvolvimento de materiais mais resistentes, mais baratos, além de novos modelos, de acordo com as tendências do mercado. Nas demais empresas, a maioria dos projetos desenvolvidos é do tipo incremental ou derivado.

Entre as dificuldades encontradas no desenvolvimento de produtos dessas empresas a mais frequente é a dificuldade de acertar o Tom Norte (nome dado ao tom de cor que mais se aproxima daquele tido como cor padrão para determinado revestimento). Esse tom se refere à cor em que deve estar o revestimento depois de pronto, no entanto, sempre ocorre de algumas unidades do produto revestimentos apresentarem tom de cor diferente dos demais do mesmo lote, ou seja, há uma variabilidade inerente ao processo. Sempre que isso ocorre esse revestimento é descartado, pois depois de assentado percebe-se com facilidade a diferença de cor entre eles. Outra dificuldade encontrada pelas empresas é realizar a reprodução do que foi definido em laboratório, dentro do orçamento da empresa, em escala industrial.

Todas as empresas desse grupo desconhecem uma ou mais das ferramentas e metodologias de apoio à gestão do PDP listadas no questionário. Desse modo foi realizada uma breve explicação para os entrevistados. Uma das empresas (16,7\%) conhece e utiliza princípios do FEMEA, QFD e benchmarking.

Outras duas empresas $(33,4 \%)$, afirmaram utilizar a ferramenta engenharia de valor. No entanto não se pôde verificar em todas as empresas que afirmaram utilizar alguma ferramenta se elas faziam realmente esse uso. 
Todas as empresas desse grupo utilizam no mínimo dois indicadores de desempenho, sendo o mais citado em 83,4\% delas a satisfação dos clientes quanto aos novos produtos; $66,7 \%$ citaram custo de desenvolvimento por projeto. Em 50\% das empresas os indicadores mais utilizados são: porcentagem do faturamento advinda de novos produtos, custo de falhas internas de novos produtos (por exemplo, o tom da cor) e porcentagem de produtos lançados dentro do tempo planejado.

Com relação ao tipo de organização das empresas do grupo 2 observou-se que em todas as empresas a organização do tipo funcional é a que mais se aproxima da estrutura de trabalho das equipes de desenvolvimento de produto.

Quanto às tendências do PDP, 66,7\% das empresas pretendem aumentar o número de lançamentos de novos produtos. Uma das empresas já estava testando novos formatos, com diferentes tamanhos e desenhos, buscando conquistar novos mercados e criar novas tendências. Além disso, 50\% das empresas esperam aumentar suas parcerias com fornecedores na expectativa de encontrar soluções para novos produtos. Uma das empresas também mencionou o desejo de formar uma parceria com universidades, buscando adquirir novos conhecimentos que possam ser utilizados na escolha de materiais, design e métodos de gestão. Nenhuma das empresas pretende implantar ferramentas de apoio à gestão do PDP, no entanto uma delas está ajustando o PDP a um sistema de informação e gestão que interage com todos os setores da empresa. Esse sistema está sendo adaptado até que atinja um formato capaz de gerar e distribuir as informações sobre o PDP para todas as áreas envolvidas no projeto. A preocupação é chegar cada vez mais próximo ao que é esperado pelo cliente final, atendendo ao que ele deseja visual e economicamente.

\section{Proposições e sugestões de melhoria}

Considerando a revisão bibliográfica e os resultados da pesquisa de campo, aplicação do questionário e entrevistas nas empresas, são apresentados a seguir algumas proposições gerais e sugestões para a melhoria do PDP das empresas. Obviamente, tais proposições devem ser avaliadas e adequadas ao caso específico de cada empresa.

Proposição 1: o desenvolvimento de novos produtos nas empresas de revestimento cerâmico está ligado à (é dependente da) capacidade de inovação dos fornecedores de insumos, principalmente os colorifícios.
Mesmo com as fabricantes de cerâmica ditando a produção dos colorifícios ficam atreladas à capacidade de inovação as fornecedoras. Um maior investimento para criação ou aumento de estruturas próprias do PDP nas empresas de revestimento cerâmico, assim como a melhoria da capacitação do pessoal responsável pelo design de novos produtos, poderia melhorar a capacidade de desenvolvimento de novos modelos e a inovação no uso de novas matérias-primas, resultando numa maior diversidade de revestimentos com o que as empresas poderiam obter maior competitividade e participação no mercado.

Proposição 2: não é prática comum nas empresas de revestimento cerâmico a utilização de ferramentas de apoio à gestão do PDP.

Como observado na pesquisa de campo, a maioria das empresas desconhece ferramentas de apoio à gestão do PDP. No entanto, algumas delas utilizam alguns princípios de tais ferramentas. Um exemplo é o benchmarking, alguns de seus princípios são frequentemente utilizados pelas empresas, mas não conhecidos por esta expressão. Esse fato não altera a qualidade ou o nível de desenvolvimento dos produtos. Mas a capacitação técnica dos funcionários ligados ao PDP, assim como dos funcionários responsáveis pela fabricação do produto, poderia ser melhorada e uniformizada nesses conceitos, bem como se poderia elevar o grau de aplicação. A aplicação adequada de ferramentas e métodos de apoio à gestão do PDP, tais como FMEA de projeto, análise de árvore de falhas, projeto de experimentos etc. pode contribuir para a melhoria da qualidade e do desempenho dos projetos e produtos.

Proposição 3: existe a necessidade de as empresas do polo se organizarem e se articularem na busca por mais vantagens competitivas.

Por dependerem tecnologicamente dos fornecedores, o tempo de desenvolvimento de produtos é geralmente maior que o das concorrentes internacionais. Para as empresas produtoras de revestimento cerâmico do polo obterem vantagem competitiva internacionalmente e aumentarem a capacidade de atuação no mercado nacional elas deveriam:

- Investir um percentual maior em P\&D e engenharia;

- Aumentar a atuação em marketing internacional;

- Realizar pesquisas de satisfação e de expectativas junto ao consumidor final;

- Aumentar a competência em design;

- Realizar parcerias junto a instituições de pesquisa e universidades, buscando elevar a competência tecnológica; 
- Utilizar mais efetivamente as ferramentas e métodos de gestão do desenvolvimento de produto;

- Buscar manter relacionamentos de longo prazo com os fornecedores; e

- Desenvolver competências para diversificar esteticamente os revestimentos cerâmicos.

\section{Considerações finais}

0 processo de desenvolvimento de produtos é um importante direcionador e indicador da competitividade da empresa. É responsável por inserir e manter a empresa no mercado, na medida em que desenvolve e aperfeiçoa produtos e serviços oferecidos por ela, no presente e no futuro. Os produtos atualmente em desenvolvimento podem assegurar a sobrevivência e boas condições financeiras para a empresa no futuro.

0 Brasil é um dos principais produtores de revestimento cerâmico do mundo. 0 Polo de Santa Gertrudes é responsável por cerca de 50\% da produção nacional e por $15 \%$ das exportações. No entanto as exportações do polo vêm crescendo a uma taxa inferior à média do estado em outros setores industriais (ASSOCIAÇÃO..., 2009). lsto se deve, em parte, a problemas na capacitação do PDP nas empresas do polo, incluindo-se a gestão desse processo. As inovações de produtos dependem tecnologicamente dos fornecedores de insumos e de equipamentos que, normalmente, são empresas multinacionais.

Analisando as dimensões do PDP, observou-se a não realização da gestão de portfólio por $45 \%$ das empresas. Nas demais empresas tal gestão é conduzida de maneira informal, ou seja, não é executada regularmente ou não se aplicam procedimentos e registros da atividade. Além disso, observa-se uma deficiência com relação à pesquisa de mercado, que é realizada de maneira informal em $70 \%$ das empresas da amostra. Essa pesquisa não é realizada com consumidores finais, sendo efetuada somente com atacadistas. Com relação à utilização de indicadores de desempenho relativos ao PDP, a maioria das empresas utiliza pelo menos um, mas não necessariamente como instrumento de avaliação e melhoria da gestão.

Na dimensão organizacional do PDP, observa-se que a organização e gestão do PDP nessas empresas são significativamente centralizadas na alta administração. Essa constatação se deve principalmente ao fato da gerência dessas empresas ser composta, principalmente, por integrantes das famílias proprietárias das empresas.

Quanto aos tipos de projeto desenvolvidos pelas empresas nos últimos três anos, observa-se que são conduzidos projetos de todos os tipos (derivados, plataforma, radicais e desenvolvimento e pesquisa avançada), mas os mais significativos são os projetos derivados e plataforma, que representam a quase totalidade.
Na dimensão atividades e informações observou-se que as atividades de PDP realizadas pelas empresas são conduzidas de maneira informal na macrofase de pré-desenvolvimento e de maneira formal nas atividades de desenvolvimento. As atividades de pós-desenvolvimento praticamente não são realizadas.

Observou-se, na dimensão recursos, que não é usual a utilização de métodos e ferramentas de apoio à gestão do PDP. No entanto observa-se que o benchmarking, CAD e Photoshop são conhecidos e utilizados por algumas empresas.

Ao se realizar as análises de grupo e de correlação, observou-se a existência de dois grupos distintos de empresas com relação às características gerais, diferenciados principalmente com relação à formalização das atividades do PDP.

Uma característica das empresas desse polo é a diferenciação por preço, que se deve ao fato de a maior parte das empresas trabalhar com processo de moagem via seca, que possui menor custo de produção, mas qualidade inferior em relação ao processo de moagem via úmida. Essa condição acaba influenciando a prioridade dada ao PDP, embora isso limite a evolução da capacidade competitiva dessas empresas, principalmente no mercado internacional.

\section{Referências}

ASSOCIAÇÃO BRASILEIRA DE NORMAS TÉCNICAS - ABNT. Disponivel em: <http://www.abnt.org.br>. Acesso em: 08 mar. 2010.

ASSOCIAÇÃO NACIONAL DE FABRICANTES DE CERÂMICA PARA REVESTIMENTO - ANFACER. Disponível em: $<$ http://www.anfacer.org.br/principal>. Acesso em: 09 mar. 2009.

CHENG, L. C.; MELO FILHO, L. D. R. QFD: Desdobramento da função da qualidade na gestão de desenvolvimento de produtos. São Paulo: Blucher, 2007. 539 p.

CLARK, K.; WHEELWRIGHT, S. C. Managing new product and process development: text and cases. New York: The Free Press, 1993.

COOPER, R. G. Winning with new products: do it right. lvey Business Journal, v. 64, n. 6, p. 54-60, 2000.

GARCIA, R.; SILVA, G. S. Relatório Setorial - Final. Finep, 2007. Disponivel em: <http://www..finep.gov.br/ PortalDPP/relatorio_setorial_final/.asp>. Acesso em: 12 abr. 2008.

KAHN, K. B.; BARCZAK, G.; MOSS, R. Perspective: establishing an NPD best pratices framework. Journal of Product Innovation Management, v. 23, n. 2, p. 106-116, 2006. http://dx.doi.org/10.1111/j.1540-5885.2006.00186.x

KAMINSKI, P. C. Desenvolvendo produtos com planejamento, criatividade e qualidade. Rio de Janeiro: LTC, 2000. p. 1-15.

MEYER, M. H. Revitalize Your Product lines Through Continuous Plataform Renewal. Research Technology Management, v. 40, n. 2, p. 17-28, 1997. 
MEYER, M. H.; LEHNERD, A. P. The Power of Product Platforms. New York: The Free Press, 1997. 267 p.

MINUZZI, R. F. B. A formação do designer de superfície na UFSM x a atuação do designer em empresa cerâmica de SC no contexto da gestão do design. 2001. 166 f. Dissertação (Mestrado em Engenharia de Produção)-Universidade Federal de Santa Catarina, Florianópolis, 2001.

ROZENFELD, H.; AMARAL, D. C.; TOLEDO, J. C. 0 processo de desenvolvimento de produto na fábrica do futuro. ln: ROZENFELD, H. A Fábrica do Futuro. Banas, 2000.

ROZENFELD, H. et al. Gestão de Desenvolvimento de Produtos: uma referência para a melhoria do processo. São Paulo: Saraiva, 2006. 542 p.

TOLEDO, J. C. et al. Gestão do Processo de Desenvolvimento de Produto em Empresas de Base Tecnológica de Pequeno e Médio Porte do Estado de São Paulo: diagnóstico e proposição de modelo de referência. 2006. 389 f. São Carlos: Universidade Federal de São Carlos, 2006. Relatório final do projeto FAPESP.

VICARI, F. M. et al. Análise das características de aglomerados de pequenas e médias empresas: os casos de lbitinga e Santa Gertrudes. In: ENCONTRO NACIONAL DE ENGENHARIA DE PRODUÇÃO, 25., 2005, Porto Alegre. Anais eletrônicos... Disponível em: <http://www. abepro.org.br/biblioteca/ENEGEP2005>. Acesso em: 01 jul. 2008.

WHEELWRIGHT, S. C.; CLARK, K. B. Revolutionizing product development process: quantum leaps, speed, efficiency and quality. New York: The Free Press, 1994.

\section{Analysis of PDP management in the ceramic tile industry pole Abstract}

This paper aims to describe and analyze the Product Development Process (PDP) management in a sample of firms from the ceramic coating pole of Santa Gertrudes, State of Sao Paulo, focusing on the identification of problems of their adopted management practices, and to propose improvements to their PDP performance, addressing the needs of the current and future capacity of these companies. A survey research was carried out through visits and interviews to 20 companies of different sizes, located at the Pole. Compilation and statistical analysis of these data were later performed. The cluster analysis and correlation indicated the existence of two distinct groups of companies with respect to general characteristics, and the main difference regarded the formalization of the PDP activities. It was also possible to observe that, in general, all companies are structured with little regard to PDP management, using few management tools, and are technologically dependent on the innovation capacity of their suppliers, mainly producers of enamels ('Colorificio').

\section{Keywords}

Product development process. Ceramic coating. Santa Gertrudes Center. Product development management. 